\title{
Suggestions to authors
}

\author{
Robert B. Daroff, MD; Lewis P. Rowland, MD; Anne Rossi; and Carol K. Scism
}

This journal transmits information from writers to readers. Competition for the limited space in Neurology is intense. Authors will be more likely to succeed in the competition if they keep their readers in mind and convey their ideas lucidly.

Write simply. Be concise. Don't ramble. Be certain your words express your ideas. State your message clearly and directly.

\section{Title of Paper}

- Keep it short.

\section{Abstract}

1. The Abstract should not exceed 150 words. Shorter is better.

2. Avoid statistical details; words suffice to carry your message.

3. Avoid sentences such as, "The implications are described." The Abstract should be meaningful by itself; it should not be a teaser.

4. In general, do not use abbreviations.

\section{General Suggestions}

1. Adhere strictly to the particular style of our journal, described in the Information for Authors in each issue of Neurology (please be sure that you are using a current issue). A manuscript submitted in the wrong style may irritate reviewers and editors and prejudice them about its scientific worth. An incorrect reference style, in particular, conveys the insulting impression that the paper was previously rejected by another journal and the style wasn't changed for the resubmission.

2. Edit your paper carefully to eliminate spelling, punctuation, and grammatical errors. After you type the "final" draft (and especially if someone else types it for you), force yourself to edit it one more time.

3. Scrupulously check the accuracy of your references. Incorrect citations are a burden on the publisher and a disservice to the reader.

4. It is not the role of the editor's office or publisher to rewrite poorly written manuscripts; that responsibility rests entirely with the authors. Those who have difficulty writing scientific English should have a proficient colleague write the paper or should seek out the services of a.professional editor who does this for a fee. (We can provide names and addresses.)

5. Organize your paper to answer the 4 main questions the reviewer and reader want answered:

- What did you set out to do and why? Introduction

- How did you do it? Methods

- What did you learn? Results
- What does it mean and how does it relate to what else is known? Discussion

It is easy to mix fact and opinion; keep the Results and Discussion separate. Keep the Discussion tightly reasoned, tightly written, and focused.

6. Avoid repetition.

- Do not repeat the Abstract in the Introduction or Discussion.

- Do not repeat the Introduction in the Discussion.

- In the text, do not repeat legends for figures, table titles, or the contents of the tables (such as values, means, or standard deviations). A paragraph full of numbers is not merely repetitious, it makes deadly reading. Using words to convey the meaning of the table keeps the message short and clear. Readers who need the precise data will turn to the table.

7. Short papers are more likely to be accepted than long ones. The length of the paper should be in proportion to the content of the information.

8. Use the active voice in the Abstract, Introduction, and Discussion. The passive voice is boring, conveys lack of conviction, requires more words, extends reading time, and may be ambiguous. The passive voice is acceptable in the Methods and Results.

9. Avoid constructions that force the reader to stop and re-read the sentence. When you find yourself using "respectively," you may recognize that you have a problem. Example: "The mean values for men and women were $x$ and $y$, respectively." Substitute: "The mean value for men was $x$, and for women, $y$." This version is unambiguous and permits the reader to proceed.

10. The color or ethnic designation of a patient is usually superfluous and should appear in a case history only if it is worth discussing-that is, if it is later mentioned in the Discussion. For color, use "black" and "white" instead of "Negro" and "Caucasian."

11. Do not use the phrase "in man." "Human" is the appropriate alternative; it can be used as an adjective or noun, is unambiguous, and does not evoke controversy.

\section{More Advice}

1. Most editors dislike "and/or." Your meaning is usually conveyed by "or" alone. If it is important, you can add "or both" at the end of the sentence. "'Subarachnoid hemorrhage can cause headache, stiff neck, or both.")

2. To the dismay of some linguistic purists, word meanings change to reflect current usage (see Webster's New World Dictionary, Third College Edition). Perhaps arbitrarily, we restrict use of the word "parameter" to its original mathematical definition (read the 
short essay on the subject in Neurology 1984;34:1591).

Similarly, "incidence rates" and "prevalence ratios" require a population denominator. Without a population denominator, the correct terms, all synonymous, are "relative frequency," "frequency," "ratio," or "percentage." "Mortality rates" requires a population denominator and a time interval. In the absence of these, deaths among a series of cases would provide a "case fatality ratio" and not a "mortality rate."

3. "CNS" should be used only if it refers to brain and spinal cord. It is not a synonym for "brain" or "cerebral."

4. "Deficit" may be used only to describe neurological signs and not symptoms. The nature of the "deficit" must be obvious from preceding information.

5. Automatic deletions - wasted words and phrases that should be deleted on sight:

prior history (all history is prior)

careful history and examination (we are all careful)

it is shown that

it is emphasized that

it is a fact that

it is known that

provided a means of

6. Some translations from medicalese:

We are accused of dehumanizing patients. Consider the following:

instead of
pediatric population
male infants
female infants
males
females
case

use

children

boys

girls

men or boys

women or girls

patient

\section{Sample Substitute Phraseology}

\begin{tabular}{ll} 
instead of & use \\
appears to be & seems \\
as to whether & whether \\
in the absence of & without \\
higher in comparison to & more than \\
chose to use & used \\
control groups & controls \\
disease process & disease \\
was found to be & was \\
due to the fact that & because \\
greater number of & more than \\
small number of & few \\
a number of & some \\
large number of & many \\
in the event that & if \\
it is possible that & may; may have been \\
interval of time & interval \\
in order to & to \\
power & strength \\
3 -month period & 3 months \\
period of time & period \\
point in time & point \\
reported in the literature & reported \\
reduced by x\% compared with & x\% lower than \\
serves the function of being & is $x \%$ less than \\
surgical intervention & surgery, operation \\
was variable & varied \\
\hline
\end{tabular}

For complete discussion on this subject, we recommend the book by E.J. Huth, Medical Style \& Format, ISI Press, Philadelphia, PA, 1987. 


\section{Neurology}

\section{Suggestions to authors}

Robert B. Daroff, Lewis P. Rowland, Anne Rossi, et al.

Neurology 1989;39;1266

DOI 10.1212/WNL.39.9.1266

This information is current as of September 1, 1989

\section{Updated Information \&}

Services

Permissions \& Licensing

Reprints including high resolution figures, can be found at:

http://n.neurology.org/content/39/9/1266.full

Information about reproducing this article in parts (figures,tables) or in its entirety can be found online at:

http://www.neurology.org/about/about_the_journal\#permissions

Information about ordering reprints can be found online:

http://n.neurology.org/subscribers/advertise

Neurology $®$ is the official journal of the American Academy of Neurology. Published continuously since 1951, it is now a weekly with 48 issues per year. Copyright (C) 1989 by AAN Enterprises, Inc.. All rights reserved. Print ISSN: 0028-3878. Online ISSN: 1526-632X.

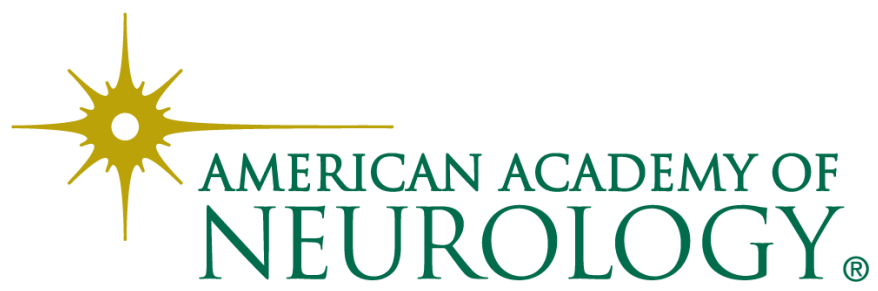

